\title{
Long term follow up of patients with cauda equina syndrome due to intraspinal lipoma
}

\author{
A Ohry MD, M Azaria MD, G Zeilig MD
}

Neurological Rehabilitation Department, Sheba Medical Center, Tel Hashomer 52621, Israel. (Affiliated to the Sackler School of Medicine, Tel Aviv University.)

We have had the opportunity to treat and follow up two young males with cauda equina syndromes after recurrent resection of intraspinal lipomas. This condition is relatively rare. The patients underwent myelographies, operations, long periods of hospitalisation, and rehabilitation. The syndromes included low back pain, arachnoiditis, and recurrence of the lipoma after several years and multiple operations.

These are the problems that we were faced with:

(1) Although the tumor is benign it is impossible to resect it completely.

(2) There are complications which interfere with rehabilitation, including pain, arachnoiditis, and neurological deterioration.

(3) Long term prognosis might be grave and the patient and family should know this.

(4) Physiotherapy and sports: should these patients perform strenuous exercise or not?

Key words: spinal lipoma; spina bifida; cauda equina syndrome; rehabilitation.

\section{Introduction}

Intraspinal lipoma is a rare condition which accounts for $1 \%$ of all primary spinal cord tumors, ${ }^{1}$ and has been described by Russell and Rubenstein ${ }^{2}$ as a pathological curiosity. According to Russell and Rubenstein ${ }^{2}$ spinal lipomas are distributed equally between the sexes and may be recognised in infancy, at puberty or in young and middleaged adults. Most intraspinal lipomas are subpial in the thoracic region and are never completely enclosed by neural tissue. Associated congenital abnormalities are found in about a third of the cases (spina bifida or other form of dysraphism). They tend to spread longitudinally over several segments, firmly blended with the nerves. In the lumbosacral area the adjacent conus medullaris tends to be abnormally low and is fixed to the surrounding tissues by fibrotic bands. Although several authors have described their clinical experience with such lesions,${ }^{3-9}$ reports on the long term follow up of such patients are uncommon. ${ }^{5}$ We present 2 patients with neurological deteriora- tion and long term follow up, and shall try to emphasise the progressive course which can be seen in patients with a lumbosacral lipoma.

\section{Case reports}

Case I: a male patient born in 1954

In 1967 this patient underwent a subtalar arthrodesis and first metatarsal osteotomy of the left leg because of increasing pain in the foot and pes cavus. A year later he was hospitalised because of stress incontinence and difficulty in defecation. Physical examination revealed right gluteus medius weakness, and areflexia of both the achilles and the left patellar tendons.

X-rays showed lumbar 5 and sacral spina bifida; and myelography revealed pressure on the cauda equina at L5-4 level.

At operation a large extra and intradural lipoma was found at that level and was partially resected. Severe lumbar nerve root malformations were also encountered. After the operation he developed a lower 
motor neuron bladder paralysis and lack of sensation below L5.

The histology of the tumour showed mainly adipose cells with some collagen. (There was no suggestion of hamartoma). During 1971 and 1972 he underwent operations for resection and closure of infected wounds of the feet, and resection of the fourth metatarsal head and tenodesis of external muscles on the left side. In 1976 he had further loss of function including right pes cavus and severe clawing of the toes. Myelography showed renewed growth of the tumour necessitating further excision of tumour and relief of the tethered spinal cord. In addition, a dense cyst full of serous liquid (hydromylia) was also removed. A year later, another arthrodesis of all of the right toes was performed. Today he still suffers from infrequent shooting pains in the L3-4 area along the posterior aspects of the thighs, double sphincter paralysis and a cauda equina syndrome. The IVP is normal. The latest neurological deterioration occurred in 1990, and he also developed a perimaleolear infection and lymphangiitis. The association could be a coincidence. Currently, he does not require any medications, and he participates in sports and works in an academic institution. The most recent MRI study (October 1990) shows no evidence of pressure on the cauda equina from the remaining lipoma.

\section{Case II: a male patient born in 1964}

During 1973 this patient gradually developed lower limb weakness. Physical examination revealed a $3 \mathrm{~cm}$ elastic mass in the midline over the L3-4 region, bilateral pes cavus, and both thighs developed a flexion posture with spasticity and hypoaesthesia below L1. X-rays showed lumbar spinal canal enlargement (in the frontal and sagittal planes), spina bifida from L2 to L5, and absence of the L2-3 laminae. Myelography revealed 'a mass' at the L2-4 region. Laminectomy was performed at that level, but no tumour was found. Some improvement was noted, but the weakness recurred a year later, together with upper and lower motor neuron signs. A further laminectomy was performed and intradural lipoma was excised, at the L3-4 levels. There was almost full neurological recovery. Histologically the tumour consisted of adipose cells, collagen and blood vessels. In 1984, while serving in the army, he suddenly developed lower limb weakness and low back pain. CT of the spine showed pressure at the L3 level, and a further operation was carried out to remove a huge lipoma and adhesions. Histologically, fibroadipose tissue was seen, with slight chronic inflammation.

The upper motor neuron signs disappeared, he walked freely and emptied his bladder by the Credé manoeuvre. He had 2 hours of intensive physiotherapy daily which included: strengthening of muscles, straightening of ligaments, gait improvement and swimming, and gradually he was able to walk unaided. Six months after the last operation he began to experience severe back pain and there was further neurological deterioration. This, coincidentally, followed erysipelas of the left leg. CTM of the spine showed that there was still remnants of the tumour compressing the neural elements. He had an incomplete spastic conus medullaris syndrome. He walked with two canes and had an asymmetrical gait. Another operation was performed, the remainder of the lipoma was removed and adhesions were divided; but the level of the spinal cord lesion rose. It was noted that he had an ascending spastic incomplete paraplegia below T11. He walked with a long leg brace on the right side using two canes, and still had double sphincter paralysis. Currently he still experiences low back pain and stiffness, but is totally independent in all activities of daily living, working every day in the family business, and there is no further neurological deterioration. The lower extremities are atrophied, more so on the right, but motor functions are normal except for dorsiflexion of the left ankle. The deep tendon reflexes are decreased bilaterally with a right Babinski response. There is spasticity of the left foot. Hypoesthesia is present below T11, but joint position sense is normal. The patient can stand and ambulate for short distances with 2 canes and a long leg brace (LLB), using a good swingthrough gait with moderate external rotation at both hips. 


\section{Discussion}

Congenital lipomas of the lumbosacral region may produce severe neurological deficits. This benign tumour of lipomatous tissue in the lumbosacral region which results from 'mesenchymal proliferative changes and ectodermal inclusion at the time of closure of the neural tube' may well enter the cauda equina via the gap of the spina bifida. ${ }^{4}$ Spina bifida occulta (SBO) is relatively common and is not usually associated with any neurological deficit. ${ }^{3,4,7,10}$ It has been recognised that shortening of the filum terminale may be associated with SBO. ${ }^{11}$ During growth, traction of the tethered cord may cause neurological symptoms. ${ }^{12}$ The condition may be familial. Intradural lipomas comprise about $1 \%$ of all spinal cord tumours. ${ }^{1,8}$ They are usually associated with bone development defects and are found in late childhood or in adults. Even subtotal resection may relieve symptoms. ${ }^{8}$ Despite the benign connotation of lipoma, these authors state that total resection is not advisable, because it is hazardous in terms of damage to the cauda equina. Eighteen cases of lipomas of the spinal cord and of cauda equina were described by Rogen et al. ${ }^{7}$ Fourteen were associated with congenital anomalies of the spine and surgical treatment was necessary.

Thomas and Miller ${ }^{9}$ have reviewed the Mayo Clinic material: they found 60 patients with intraspinal lipomas over 50 years, and concluded that the exact determination of the interval from onset of the symptoms to the time of surgery was not only difficult $^{13}$ but was also of limited value, since 'nonclinical circumstances' are involved.

Generally, the clinical manifestations are the same as for other mass lesions of the cauda equina: pain, weakness, alteration of muscle tone and of sphincter function. Usually, a rehabilitation programme could be given on an outpatient basis. Sometimes laminectomy alone is sufficient according to these authors: 'subtotal tumour removal does not seem to enhance the patients' chances greatly'. We do not fully agree with this statement, although we appreciate that it is quite difficult to excise the tumour completely. Because of the nerve bundles' proximity to the lipoma, the combination of laminectomy with subtotal resection is usually the operative procedure of choice. $3,5,6,10,14,15$

The literature quoted above usually deals with the surgical problem or the final neurological outcome, but there are only a few articles concerning the various long term aspects. ${ }^{16,17}$

There are some specific aspects concerning this clinical entity:

1 These patients usually undergo multiple myelographies, spinal operations and many hospitalisations.

2 They usually experience gradual neurological deterioration. Should they and their families be informed about the 'natural history' of the disease: pain, bladder dysfunction, ${ }^{18,19}$ adhesions, arachnoiditis, etc?

3 Should they know from the beginning about the possibility of recurrence of the tumours?

4 Although this is a benign tumor, it can cause paraparesis or paraplegia. Sometimes, after the first operation, there is relief and some hope, but in later years deterioration is inevitable. Thus the question arises whether to reoperate or not. Is laminectomy necessary? Should these patients be allowed to participate in sports? The rehabilitation programme should contain anti-pain modalities, physiotherapy, sphincter education and sexual counselling.

5 Whether this is a coincidence or not, in both of our patients the latest neurological deterioration occurred after leg infection, a fact not fully comprehensible to us.

6 Repeated MR of the spine is recommended as the most sensitive measure for tumour regrowth. ${ }^{12.20-23}$

7 During the operations, it is advisable to monitor the spinal nerve roots by evoked potential and peripheral nerve compound action potential in order to prevent resection of viable neural tissue. ${ }^{24}$

In our opinion, careful consideration for reoperation should be given and performed only when there is clear evidence of direct pressure on the cauda equina.

The patients and their family should be 
informed about the whole aspect of this situation. Sports and physical exercise should be encouraged. Hospitalisation is not required for the rehabilitation programme.

\section{References}

1 Ammerman BJ, Henry JM, De Girolami V, Earle KM (1976) Intradural lipomas of the spinal cord-a clinicopathological correlation. J Neurosurg 44: 331-36.

2 Russell DS, Rubinstein LJ (1989) Tomography and Tumor-like Lesions of Maldevelopmental Origin in Pathology of Tumors of the Nervous System. 5th ed. Edward Arnold, London: 706-708.

3 Balagura S (1984) Late neurological dysfunction in adult lumbosacral lipoma with tethered cord. Neurosurg 15: 724-6.

4 Bassett RC (1950) The neurologic deficit associated with lipomas of the cauda equina. Ann Surg 131: $109-16$.

5 McLone DG, Naidich TP (1986) Laser resection of 50 spinal lipomas. Neurosurg 18: 611-615.

6 Pasternak JK, Volpe JJ (1980) Lumbrosacral lipoma with acute deterioration during infancy. Pediatrics 66: 126-126.

7 Rogen HM, Long DM, Chou SN, French LA (1971) Lipomas of the spinal cord and cauda equina. J Neurosurg 34: 349-354.

8 Swanson HS, Barnett JC (1962) Intradural lipomas in children. Pediatrics 48: 911-926.

9 Thomas BE, Miller H (1973) Lipomatous tumors of the spinal canal. Mayo Clin Proc 48: 393-400.

10 Robinson SC, Sweeny JP (1983) Cauda equina lipoma presenting as acute neuropathic arthropathy of the knee. Clin Orthop 178: 210-213.

11 Love JG, Daly DO, Harris LE (1961) Tight filum terminale-report of condition in three siblings. J Am Med Assoc 176: 31-33.

12 Raghavan N, Bazkovich AJ, Edwards M, Norman D (1989) MRI in the thethered spinal cord syndrome. Am J Roentgenol 152: 843-852.

13 Van Dellen JR, Van den Heever CM (1976) Intraspinal lipoma. S A Med J 50: 49-50.

14 Aoki N (1990) Rapid growth of intraspinal lipoma demonstrated by MRI. Surg Neurol 34: 107-10.

15 Begeer JH, Wiertseema GP, Breukers SM, Mooy JJ, ter-Weeme CA (1989) Tethered cord syndrome: clinical signs and results of operation in 42 patients with spina bifida aperta and occulta. Zeitschriff fur Kinderchirurgie 44 (suppl 1): 5-7.

16 Weissert M, Gysler R, Sorensen N (1989) The clinical problem of the tethered cord syndrome. Zeitschraft fur Kinderchirurgie 44: 275-279.

17 Gabay C, van Linthoudt D, Ott H (1989) Lumbosacral spina bifida associated with an intraspinal lipoma. Schweizerische Medizinische Wochenschrist 119: 1604-8.

18 Foster LS, Kogan BA, Cogen PH, Edwards MS (1990) Bladder function in patients with lipomyelomeningocele. J Urol 143: 984-6.

19 Onishi N, Kiwamoto H, Esa A, Sugiyama T, Paku YC, Kaneko S et al (1989) Neurogenic bladder dysfunction due to tethered spinal cord syndrome in adults. Hinyokika-Kiyo 35: 1229-1234.

20 Monfarrij NA, Palmer JM, Hahn JM, Weinstein MA (1989) Correlation between MRI and surgical finding in the tethered spinal cord. Neurosurg 25: 341-346.

21 Okumura R, Minami S, Asato R, Konishi J (1990) Fatty filum terminale: assessment with MR imaging. J Comput Assist Tomog 14: 571-573.

22 Gupta RK, Sharma A, Jena A, Tyagi G, Prakush B et al (1990) MR evaluation of spinal dystrophism in children. Child Nerv Syst 6: 161-165.

23 Tortori DP, Cama A, Rosa ML, Andreussi L, Taccone A (1990) Occult spinal dysraphism: neurone histological study. Neuroradiol 31: 512-522.

24 Phillips LH, Park TS (1990) Electrophysiological monitoring during lipomyelomeningocele resection. Muscle and Nerve 13: 127-132. 